\title{
PHILOSOPHY OF SCIENCE
}

T HE sixth annual conference of the British Society for the Philosophy of Science was held at St. Hugh's College, Oxford, during September 22-24. The four formal meetings and discussions, once again organized by Dr. Mary Hesse (Cambridge), were attended by eighty members and guests.

The theme of the first meeting, with Dr. B. A. Farrell (Oxford) in the chair, was explanation in psychology. The first of the two papers was read by Dr. M. Treisman (Oxford), who challenged the widespread belief that, whereas the physical and biological sciences use only public data, the psychologist also uses private data of immediate experience. Dr. Treisman's method was to select topies from the history of psychology to show that the modern psychologist has refined the vague descriptive analyses of the past and now uses concepts as precisely definable and as objective as those of the physicist. The first illustrative topic he discussed was the analysis of instinct. He contrasted McDougall's classification analysis, vague and merely descriptive, with the present-day model of instinctive behaviour in animals based on the work of Lorenz and Tinbergen. Here there was little to dispute though the argument edged close to the controversial issue of reductionism. His second topic was the history of the measurement of sensation: he described the experiments of Fechner and of Stevens and Davis which led to the apparently conflicting laws $S=K$ $\log I$ and $S=K I^{n}$ respectively, where $S$ is the 'measure of sensation' and $I$ is the intensity of the stimulus. Dr. Treisman argued that these laws could be reconciled but that the second was preferable because it had more explanatory power.

Dr. J. O. Wisdom (London School of Economics) widened the scope of the kind of psychological explanation to be considered by discussing the hypotheses used by psychoanalysts to explain patients' associations. Such an explanation, he argued, requires to be tested clinically by observing the patient's response to a presentation of an interpretation embodying the hypothesis. But, following Seeborn Jones, he indicated that two problems then arise: Does the presented interpretation cause a change ? Is the interpretation true? He proffered some new criteria to distinguish between an interpretation that causes a change by suggestion and an interpretation that is true.

A long and lively discussion ensued. The chairman began by challenging the assumption implicit in Dr. Wisdom's paper that the reports of the psychoanalyst could be regarded as objective data, but, for an hour, discussion was focused on Dr. Treisman's reconciliation of the two laws of sensation, a reconciliation which failed to satisfy the mathematicians present. Eventually there was a return to psychoanalysis: What are its basic statements ? To what extent could the reports of the analyst about his subject be regarded as objective data? But again the discussion returned to the measurement of sensation. How could 'half a feeling' be measured ?, the physicists demanded. Various solutions to the many problems raised echoed along the corridors of St. Hugh's until well after midnight.

At the next session the president, Prof. R. B. Braithwaite (Cambridge), took the chair for a dis- cussion on learning machines. Dr. F. H. George (Bristol), treading delicately over this philosophically thorny field, outlined some of his recent work. He gave a lively description of his method of programming a Deuce computer so that one-half of the machine taught the other half to play an optimal game of noughts and crosses - a by no means trivial game, as the chairman had later occasion to emphasize. Dr. George went on to explain more generally how a computer can 'learn' to generalize from its own experience and to symbolize or 'name' the pro. cesses it goes through. He suggested that such performances give the computer qualities analogous to the insight and flexibility of human thought. processes.

Prof. D. M. Mackay (North Staffordshire) gave a thoughtful elaboration of Eddington's account of 'the two tables' extended to persons (and their brains) and to machines. He first considered the transition from the micro-description of a mechanism to its behavioural description in such terms as 'controlling' and 'goal-seeking'. He argued that such behavioural terms presuppose an under-specification of the physical situation which becomes meaningless when applied to mechanisms specified in atomic detail. He then extended his analysis to 'game-playing' mechanisms and explained how the crucial difference between playing against and manipulating a machine lies in the nature of one's commitment towards it. Finally, he extended his analysis to human beings, regarded as persons and as cell-mechanisms, and discussed the degree to which it is possible to switch from one view to the other when one is confronted by another human being.

In the discussion Dr. George was asked to elucidate some technical points, but members' questions mainly sought clarification of Prof. Mackay's concept of under-specification, its relation to entropy and its implications for personal commitment in dialogue.

The third meeting was devoted to a discussion of genetic coding and information theory, with $\mathrm{Mr}$. F. T. C. Harris (Middlesex Hospital Medical School) as chairman. Dr. I. Leslie (Belfast) gave the first of two papers. Using a helpful series of slides, he reviewed with modest impartiality some recent developments in the biochemical analysis of the processes by which information is transferred from the genes to the cellular sites of protein synthesis. He explained the background to the present conflict of ideas about the way in which ribonucleic acid (RNA) acts as an intermediary in this transference. In the 'classical' view much of the RNA is in the form of stable templates which are coded by DNA for the synthesis of specific proteins: but recent experiments on bacteria and bacterial viruses suggest that some of the RNA acts as a 'messenger' which itself carries genetic information from the genes to the proteinsynthesizing mechanisms.

The second main speaker, Dr. S. Brenner (Cambridge), remarking that "philosophers are not really concerned with the facts", bounded gaily from Dr. Leslie's well-laid factual foundations into genetic space. He delighted the audience with bold speculative leaps and a frank analysis of his own approach to the problem. He based his study of genetic coding. he explained, on two main principles: (1) that "any- 
thing useless must be wrong", and (2) that "there is no security problem in Nature", that is, Nature is no enemy striving to concoal the truth from us. He then attacked the view that the stable RNA of the ribosomes acts as a template and argued that the ribosomes are structures which synthesize, at a given time, the protein dictated by the attendant messenger. Thus he rejected two- and three-procoss models of transfer of information in favour of a one-process model which he claimed was universal.

The discussion was at first confined to thrust and counterthrust between the two experts, deftly provoked by the chairman. But gradually the audienco gained sufficient confidence to intervene. Questions about the evolution and the controlling mechanisms of this complex system (for example: How do you make a cat ?) led to lively discussions. It slowly became apparent that though genotic coding was concerned with transfer of information, information theory itself had little to offer in solving the problems of genetic coding apart from providing some descriptive terms. As Dr. Brennor put it in his final remark, "It's now just a matter of linguistics", that is, of reading the code.

The fourth and final discussion was devoted to philosophical aspects of cosmology. Prof. J. L. Mackie (Sydney) took the chair, and Mr. R. Harré (Oxford) and Dr. W. Davidson (Battersea College of Technology) were the two main speakers. Mr. Harré argued that tho universe, defined as 'everything there is', was logically not a proper subject for scientific study. He carefully distinguished between the cosmosciences and the astro-sciences by analysing the logical form of typical propositions of those subjects; though cosmography, he thought, could be regarded as scientific, the other cosmo-sciences, cosmogeny and cosmophysies, were merely spoculative. His main attack centred on the concept of infinity as used in or implied by the cosmo-sciences: he distinguished between the concept of an actual or referential infinity, which he rejected as logically improper, and the concept of a descriptive infinity which (analog. ously with the intuitionist concept of infinity in mathematics) has a finite starting point and a rule of progression which may continuo without limit and thus be a growing but potentially infinite sequence.

Dr. Davidson argued that development of the cosmo-sciences was scientifically both volid and feasible, and that such questions as whether the universe is spatially infinite or not, or whether it had an origin in time or not, are not necessarily transcendental issues. He claimed that the unity of science as a whole may depond on the development of a satisfactory cosmology in which every science could find its place.

With the two protagonists thus apparently diametrically opposed, the chairman formulated their main differences and members of the Conference set about their task of resolving them. In the discussion, Mr. Harré's dependence on Kantian antinomies, Russell's theory of types, and a priori arguments took some hard knocks. It scemed eventually that perhaps only the philosopher's concept of the universe was referentially infinite, while the cosmologist's univorse, if not finite, was at worst only descriptively infinite and therefore not, logically, a wholly improper subject of study.

The conference ended with a businoss meeting at which, inter alia, members were able to express their thanks to St. Hugh's College as hosts and to Dr. Mary Hesse as organizer for the parts they played in a pleasant and stimulating week-end.

B. C. Brookes

\section{IONIC MELTS}

T IQUIDS still constitute one of the least well 1 understood states of matter. Near the critical temperature various quasi-gaseous formulations of their behaviour are often quite successful, but near the melting point quasi-crystalline models offer more promise. Ionic melts have been much less studied than many other liquids. Their critical temperatures are usually not known, but are certain to be high. For this reason, current structural models for ionic melts show a bias towards quasi-crystalline concepts, which is strengthened by the strong statistical probability that each cation will have anions as its nearest neighbours, and vice versa, in order to lessen electrostatic repulsion energy.

However, really precise theories of the structure of ionic melts present difficulties which have not yet been surmounted. In addition to the theoretical difficulties, until recent years the amount and diversity of experimental work on ionic melts has been restricted by technical complications. Temperatures of study need to range from $100^{\circ}$ to well above $1,000^{\circ} \mathrm{C}$., and many of the melts attack practically every kind of containing wall. Despite these obstacles, interest in the science and technology of ionic melts has been growing rapidly. Sessions dealing with these systems have been included in a number of recent international scientific meetings, and two Gordon conferences in the United States have been wholly devoted to discussing their properties. At the discussion meeting of the Faraday Society, held in the University of Liverpool during September 5-7, seventy-five scientists from Britain and fifty from overseas had the opportunity of comparing progress in three main fields: structure, thermodynamic properties, and transport properties of ionic melts. The president, Sir Cyril Hinshelwood, was in the chair. Prof. H. Bloom, of the University of Tasmania, gave the eleventh Spiers Memorial Lecture on "Structural Models for Molten Salts and their Mixtures".

A broad conclusion from the discussion was that interesting and important oxperimental work is being carried out in quite a fow centres. Comprehensive theoretical treatments of the properties of ionic melts have by no means caught up with the range or the physical interest of the data now being obtained. Applied research on ionic melts in electrometallurgy or as heat-transfer fluids appears to be reasonably active in various countries. The number of substances capable of existence as stable liquids in the range $300-1,000^{\circ} \mathrm{C}$. is comparatively small, which points to the profitability of exploring further fields of application of ionic melts. At present, basic research on ionic melts seems scanty in British universities, 